\title{
Application of New Approaches to the Hydropower Combined Complex Creation for Autonomous Energy Supply
}

\author{
A. V. Volkov ${ }^{1}, A . V$. Ryzhenkov ${ }^{1}, A . A$. Druzhinin $^{1 *}, A . A$. Vikhlyantsev $^{1}, B . M$. \\ Orakhelashvili $^{1}$, V. N. Baikov ${ }^{1}$, Jiř́ Š Šukal ${ }^{2}$, Milan Sedlař ${ }^{2}$ and Martin Komárek ${ }^{2}$, František \\ Pochylý $^{3}$, Pavel Rudolf ${ }^{3}$ and Simona Fialová ${ }^{3}$ \\ ${ }^{1}$ FSBEI HE National Research University MPEI, Moscow, Russian Federation \\ ${ }^{2}$ Hydraulic Research Center "Sigma" spol. s r.o., Lutín, Czech Republic \\ ${ }^{3}$ Brno University of Technology (BUT), Brno, Czech Republic
}

\begin{abstract}
The report examined new scientific approaches to the creation of a combined cogeneration energy complex based on small or microhydropower. The most effective approaches to micro-hydropower facilities were considered to create a workable structural layout. A criterion has been developed that allows to evaluate the energy efficiency of hydroturbines at an early stage of design using the calculation method, including a predictive estimate of the hydraulic resistance function $\xi_{\mathrm{HT}}=f(R e)$ of a particular penstock geometry. The results of the theoretical task of creating a technologically advanced configuration of a blade system using Zhukovsky theory. By calculating and numerically (CFD) simulating the hydrodynamic lattices of flat profiles, the theoretical nomograms for determining the coefficients $C_{x}$ and $C_{y}$ are confirmed and supplemented. A series of comparative results of computational and experimental studies of the combined energy complex hydraulic part - microhydroturbines with experimental blade systems, including those modified by the principle of biomimetics (nature imitation technologies) is presented. Based on the calculated and experimental studies, the prospects of the chosen direction of development of small and microhydroenergy are shown, as well as the effectiveness of the approaches that were used in the design of the working bodies of microhydroturbines.
\end{abstract}

\section{Introduction}

Developed countries in Europe (for example, the Czech Republic, the Slovak Republic, the Russian Federation) are similar in terms of water resources and terrain features. The hydropower potential of these countries in modern conditions is almost fully utilized with the help of generating capacities of large hydropower plants. However, questions on the energy supply of decentralized (autonomous) consumers, often geographically located near small rivers and other water bodies, with small geodetic heads of about 2-3 m and low disposable

* Corresponding author: alexey2959@mail.ru 
flow rate have not been removed from the agenda (figure 1). Therefore, the task of creating highly efficient energy sources based on environmentally friendly technologies and using renewable energy sources for autonomous energy supply is very urgent.

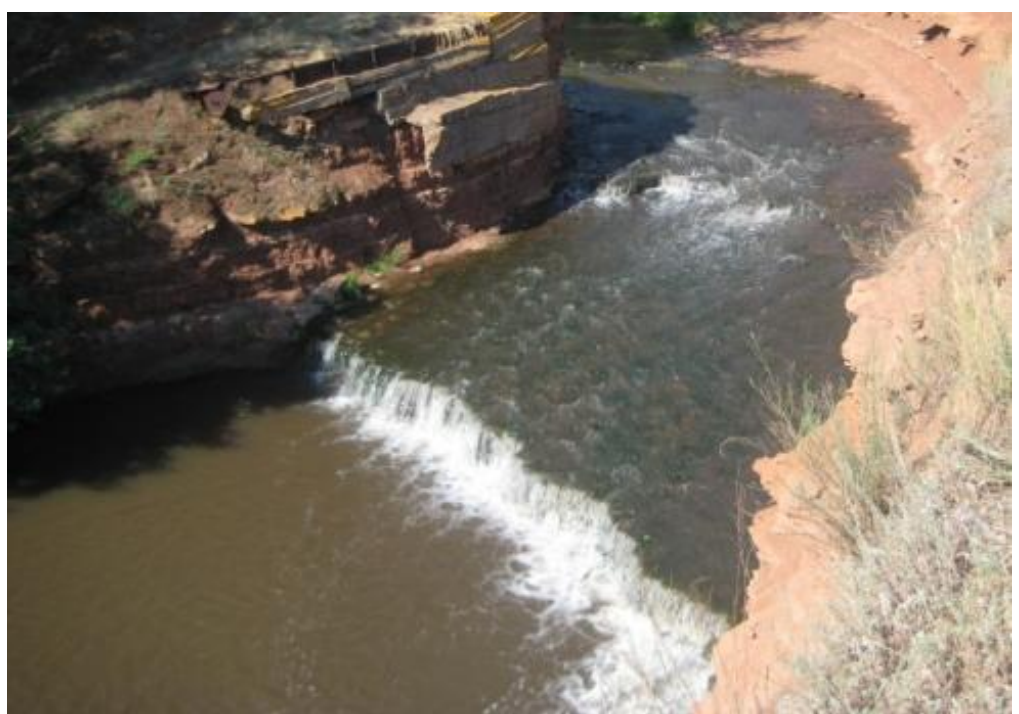

Fig. 1. An example of a low-head water drop, Ural River, Russia.

\section{Development of schematic solution}

During the development of the concept of creating a combined energy source, a scheme for the combined power supply of an autonomous consumer based on micro HPP [1] with a builtin axial-type turbine in the siphon penstock was proposed (figure 2).

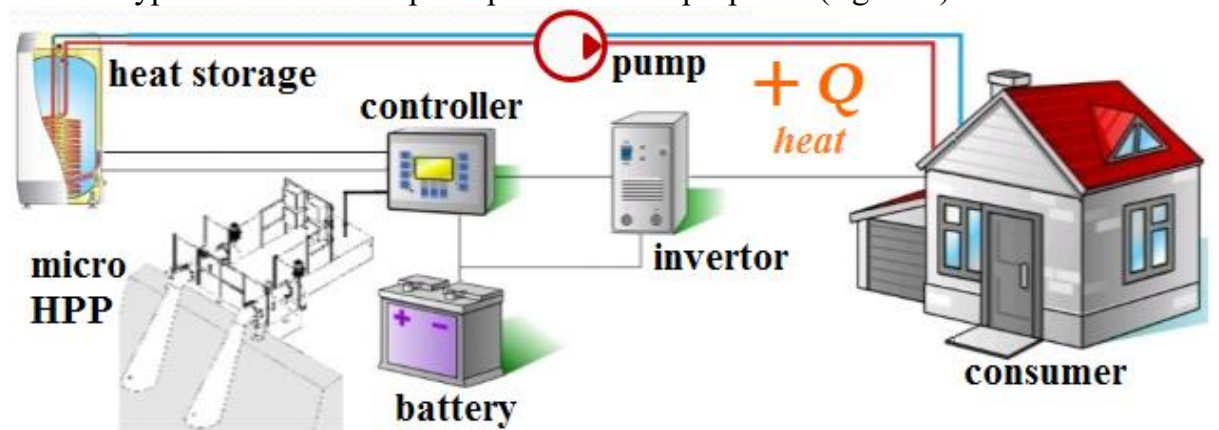

Fig. 2. Autonomous energy supply scheme based on micro HPP.

This scheme solution allows to provide follow:

- stable and reliable operation within the daily cycle;

- increased manoeuvrability with discrete power control;

- the use of several hydraulic units of various power capacities for emergency backup;

- the principle of modularity (increasing installed power capacity depending on the needs of the consumer).

An analysis of the possibility of using various design schemes of micro HPP during its development showed that the task of creating a combined energy source under low-heads $(H=2-3 \mathrm{~m})$ for the hydropower industry under consideration is much more complicated. 
This is due to a number of factors, among which it is necessary to especially note the low efficiency of the types of hydraulic machines in the field of small available heads.

\section{Method for preliminary assessment of the effectiveness of microhydroturbines}

The variety of natural and climatic conditions of our country, as well as the lack of existing types of hydraulic machines that can work effectively in conditions of low head and flow rate have led to the need to use new approaches to their design. Based on the problems posed an improved method of micro HPP propeller hydraulic turbine designing built-in penstock was developed $[2,3]$. It consists in a preliminary assessment of the energy efficiency of micro HPP and allowing to optimize the design parameters of a hydraulic turbine in its composition at the early stages of design. The energy efficiency of a hydraulic turbine as part of a micro HPP is estimated by the energy utilization coefficient $K_{N}$.

$$
K_{N}(h, \eta)=N_{\mathrm{HT}} / N=\eta \sqrt{1-\eta(2-\eta)},
$$

where $N$ - the available flow power of penstock, $N_{H T}$-hydraulic turbine power, $\eta$ - the hydraulic turbine efficiency, $h=H_{H T} / H_{a v}$ - head utilization coefficient as the ratio of the hydraulic turbine theoretical head $H_{\mathrm{HT}}$ to the available head of the penstock $H_{\mathrm{av}}$.

Function (1) is numerically describing the proportion of the available hydraulic energy of the penstock that hydraulic turbine triggered when established in flow part. Function $K_{N}(h, \eta)$ maximum is achieved at the maximum value $\eta=\eta_{\max }$ and the optimal value of $h$ corresponding to the zero value of the first derivative of the function $K_{N(h, \eta)}$ :

$$
h_{\text {opt }}=\frac{2}{3\left(2-\eta_{\max }\right)},
$$

Figure 3 presents a graphical interpretation of the energy efficiency limit of microhydroturbines of various typal sizes $(\eta=$ var $)$ :

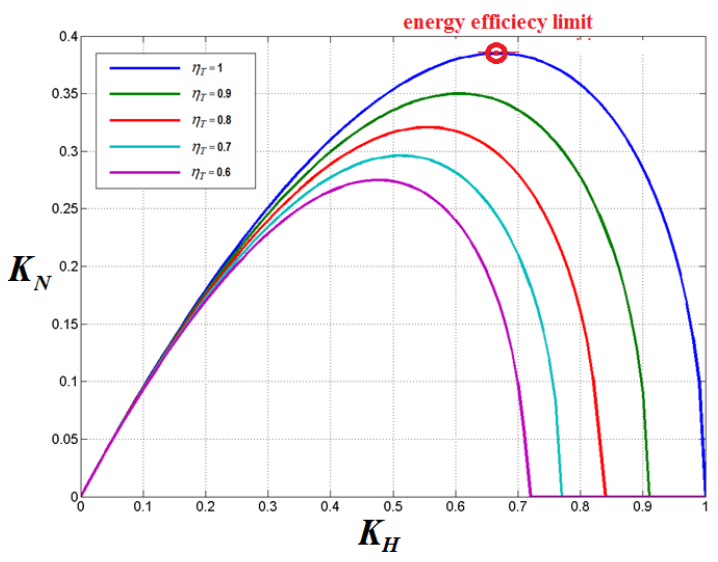

Fig. 3. Graphic illustration of energy efficiency limit.

This limit for a hydraulic turbine installed in a penstock is a hydraulic analogue of the Betz-Zhukovsky limit that known in the theory of wind energy [4] and allows to evaluate the energy efficiency of a hydraulic turbine as part of micro HPP at the early stages of design, as well as to more competently optimize its design parameters. 


\section{Creating a blade system using Nicholas E. Zhukovsky theory}

In order to simplify manufacturing, reduce costs technology in the manufacture of microhydro impeller considered the possibility of designing a blade system consisting of flat profile. The task of designing such an impeller involves use of Nicholas E. Zhukovsky theory. A feature of the application of this theory is the determination of the resultant of all forces acting on the flat profile of the blade using the equations (3), (4) for finding projection components:

$$
\begin{aligned}
& P_{x}=C_{x} \rho \frac{w^{2}}{2} l, \\
& P_{y}=C_{y} \rho \frac{w^{2}}{2} l .
\end{aligned}
$$

The use of these expressions implies the determination of $C_{x}$ drag coefficient and $C_{y}$ lifting force of the profile coefficient. Usually, the Voznesensky-Pekin method and the corresponding nomograms proposed by Alexander A. Lomakin [4] and Vyacheslav V. Barlit [5] are used for this. However, these nomograms allow to determine only $C_{x}$ drag coefficient. To supplement the missing data for the design, a Russian calculation package of applied programs "FlowVision" was used. For this purpose, the values of the $C_{x}=f(l / t)$ existing nomogram were obtained by the calculation-experimental method to assess the reliability. Later, based on the results of a successful assessment of the convergence of the calculated and calculated-experimental results, a new nomogram $C_{y}=f(l / t)$ was obtained. This made it possible, with a sufficient degree of reliability, to determine the parameters of the impeller blade system.

In figure 4 dashed lines represent $C_{x}=f(l / t)$ known nomogram values, which are compared with the main lines of the confirming results of the calculation and experimental study of the $C_{x}=f(l / t)$ nomogram.

In figure 5 shows the new data: the $C_{y}=f(l / t)$ nomogram obtained by the calculationexperimental method which is necessary to supplement the input parameters when designing a blade system.

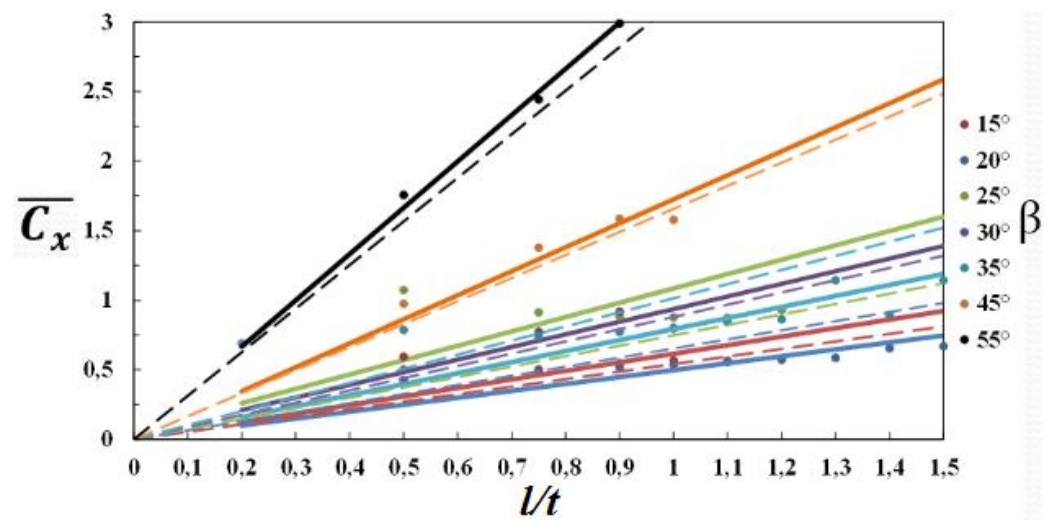

Fig. 4. Results of the $C_{x}=f(1 / t, \beta)$ nomogram verification. 


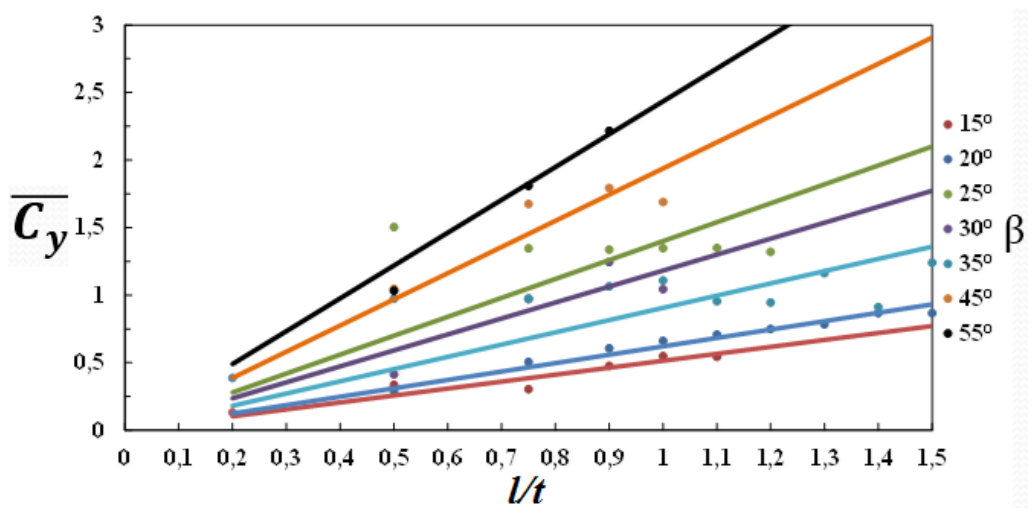

Fig. 5. $C_{y}=f(1 / t, \beta)$ nomogram obtained by the calculation and experimental method.

Thus, it is shown that the results of computational and theoretical studies of the hydrodynamic grid of flat profiles with variable parameters (the profile length 1 , the blade angle $\beta$, the grid pitch $t$ ) can be used with a sufficient degree of reliability to create blade systems using the Nicholas E. Zhukovsky theory. The results supplement the data of wellknown nomograms and make it possible to use the hydrodynamic characteristics of a single profile for the design of hydrodynamic grids and to adjust the midline of the profile in them. Research in this direction was also carried out at the Brno University of Technology, the results of which are optimization of the hydrodynamic grid in torque [6].

These computational and theoretical studies were carried out in CFD code using the Czech automated multi-machine computing station "Sigma" for the design and optimization of hydrodynamic machines and systems, as well as Russian computational software "FlowVision" directly for modeling. The impeller (figure 6) created in the new configuration has 8 blades in the form of flat plates and is designed for the following design parameters:

- $\operatorname{power} N=25 \mathrm{~W}$;

- rotation frequency $n=1000 \mathrm{~min}^{-1}$;

- design head $H_{d}=0,84 \mathrm{~m}$;

- impeller diameter $D=80 \mathrm{~mm}$.

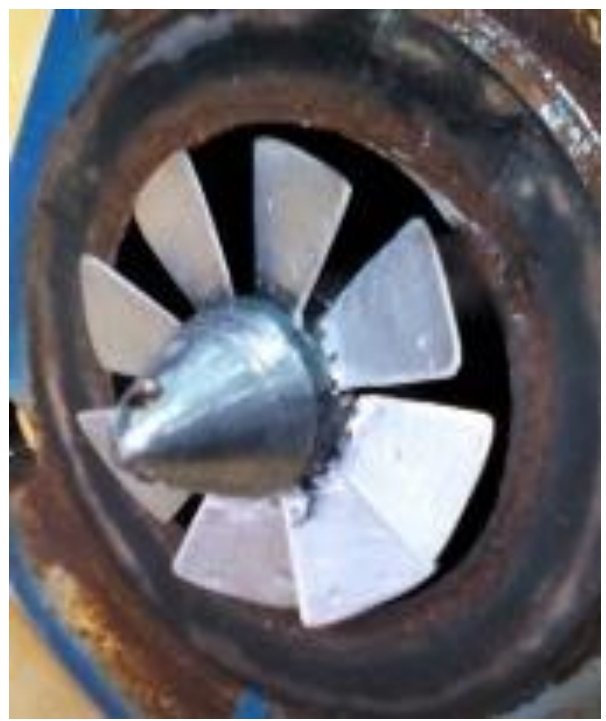

Fig. 6. Impeller designed using Nicholas E. Zhukovsky theory. 
For the purpose of confirming the operability and the combined energy complex hydraulic part, its model was created which consists of a hydraulic turbine built-in siphon penstock and an electric machine control system. It was experimentally tested using the hydrodynamic channel of the "MPEI" Hydroaeromechanics Laboratory. $N=f(n)$ power characteristic which obtained from experimental studies showed $N_{\max }=18 \mathrm{~W}$ at the calculated rotational frequency. Its appearance is shown in figure 7.

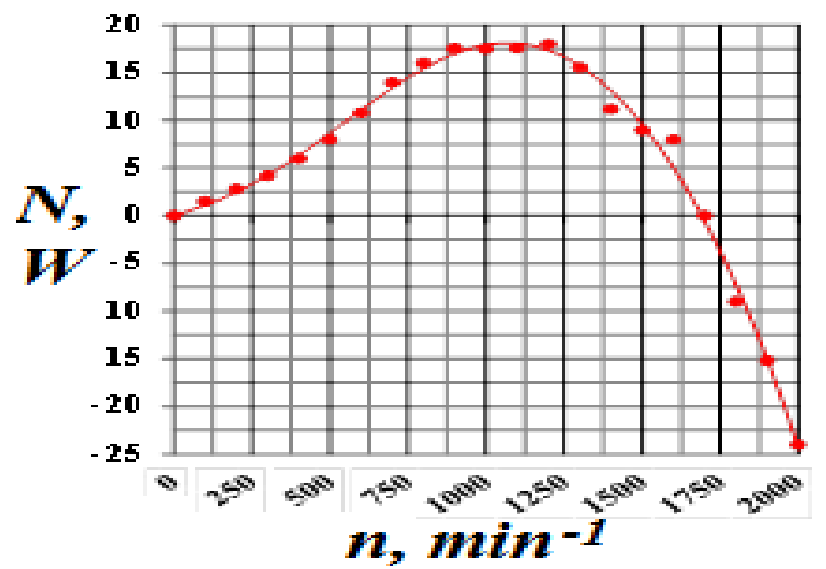

Fig. 7. Experimental characteristic $N=f(n)$ of the micro HPP model.

To increase the reliability of the obtained results, based on the existing infrastructure of the "MPEI" Hydroaeromechanics Laboratory (figure 8), a maquette of the combined energy complex hydraulic part with the following design parameters was created:

- $\quad$ power $N=1500 \mathrm{~W}$;

- $\quad$ rotation frequency $n=1000 \mathrm{~min}^{-1}$;

- $\quad$ design head $H_{d}=2,5 \mathrm{~m}$;

- impeller diameter $D=250 \mathrm{~mm}$.

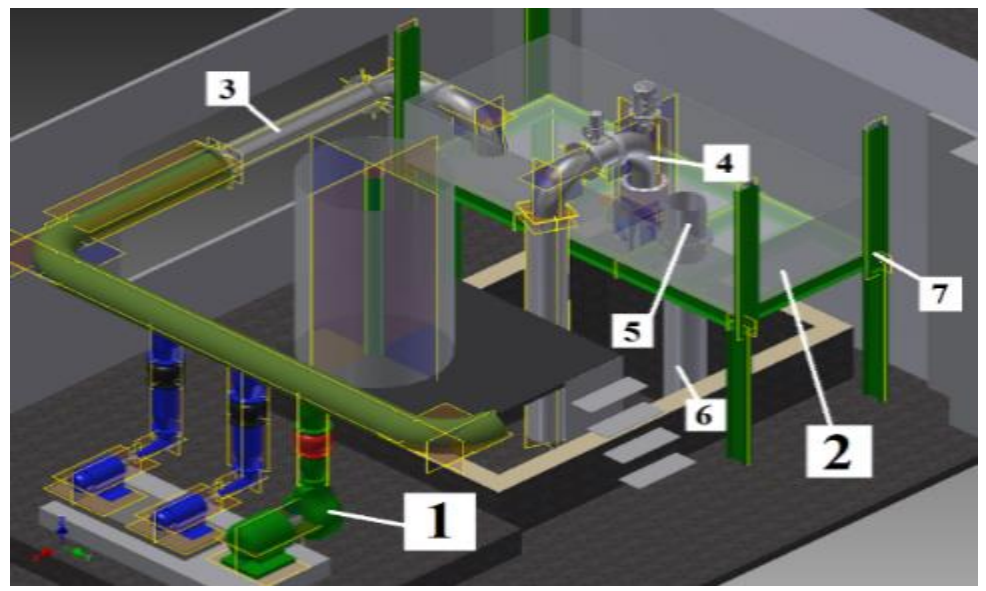

Fig. 8. 3D-model of the experimental stand - a maquette of the combined energy complex hydraulic part: 1 - stand circulation pump, 2 - upstream reservoir, 3 - pressure pipe, 4 - siphon penstock with hydraulic turbine and electric machine assembly, 5 - overflow pipe, 6 - downstream reservoir.

According to the results of experimental studies of the maquette, an oscillogram $N$, $n=f(t)$ of the most important parameters of the hydraulic part of the complex - power and 
rotational frequency was obtained (figure 9). Its appearance shows three main operating modes - pump, transition and generator (main mode).

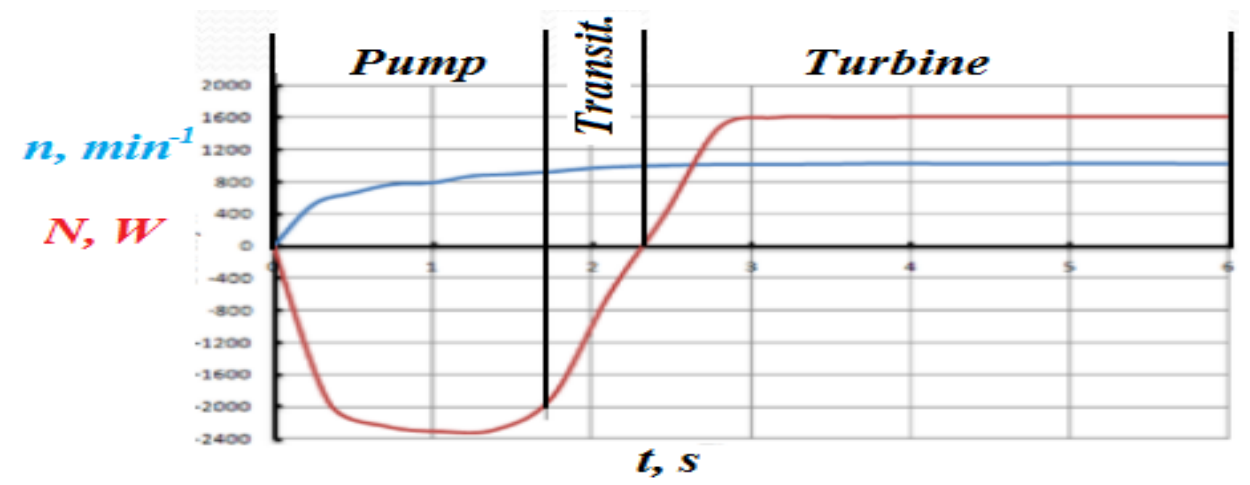

Fig. 9. Oscillogram of the complex hydraulic part parameters.

The analysis of the oscillogram shows that the design of the impeller blade system must be carried out in the pump mode to ensure guaranteed filling of the flow part when the energy complex is switch-on into operation.

\section{Improving the blade system of a hydraulic turbine to increase efficiency}

The impeller which created earlier is characterized by a high density of the blade system. It greatly complicates the operation of a microhydroturbine in real conditions. For example, in the flood period, when the probability of foreign objects getting into the flowing part is high.

In order to minimize the risk of loss of performance in such conditions, the impeller was designed for the same design parameters as the 8-blade impeller, but using classical approaches to the design of microhydroturbines. The impeller with a new blade system (figure 10) is characterized by a smaller number of blades $(z=3)$ for a significant increase in the size of the inter-blade channel and the impeller blades are profiled in three characteristic sections.

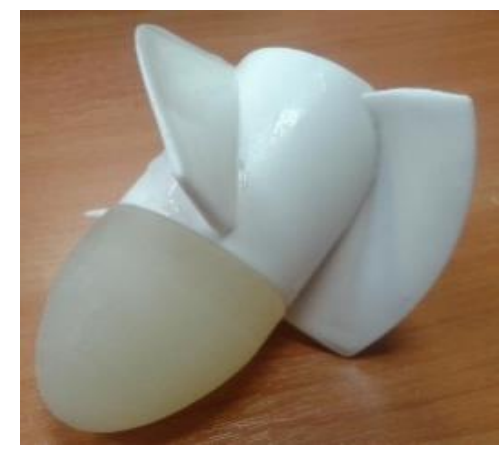

Fig. 10. Impeller designed using classic approaches.

In figure 11 shows diagrams of the pressure distribution $\mathrm{P}$ in the width $\mathrm{S}$ of the impeller inter-blade channel according to the results of CFD-modeling in the FlowVision software. 


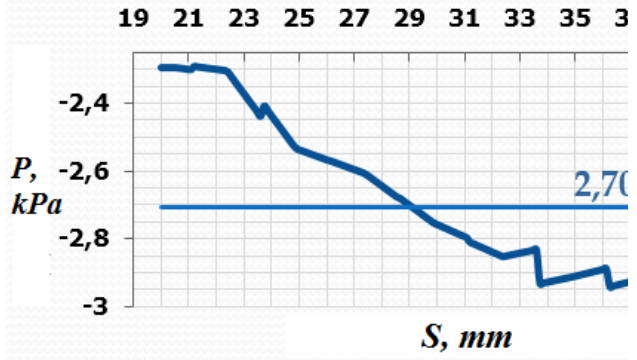

(a)

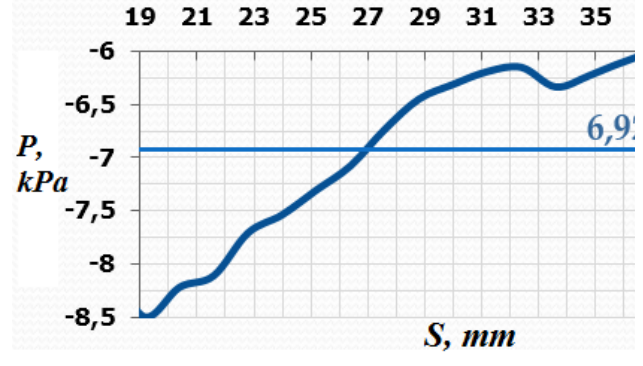

(b)

Fig. 11. Diagrams of pressure distribution in the inter-blade channel of the impeller: (a) - at the input; (b) - at the output.

Analysis of the data obtained as a result of plotting allowed to estimate the pressure drop which on the impeller was $\Delta P=4,2 \mathrm{kPa}$.

A comparative assessment of the energy qualities of a microhydroturbine with the original and new impellers obtained as a result of virtual calculations is summarized in table 1.

Table 1. Comparative energy characteristics of microhydroturbine.

\begin{tabular}{|c|c|c|}
\hline Impeller & Power $\boldsymbol{N}(\mathbf{W})$ & Torque $\boldsymbol{M}_{\boldsymbol{t}} \mathbf{( N \cdot m )}$ \\
\hline Original $(z=8)$ & 9.95 & 0.103 \\
\hline New $(z=3)$ & 16.9 & 0.152 \\
\hline
\end{tabular}

In order to identify the correspondence of the impeller to the typical type of pressure characteristic inherent in axial hydraulic machines, its design studies were carried out in the pump mode. The results are presented in Figure. 12. The obtained head characteristic of the impeller under study, having a specific speed coefficient is $n s=635$ which demonstrates the usual form for axial pumps.

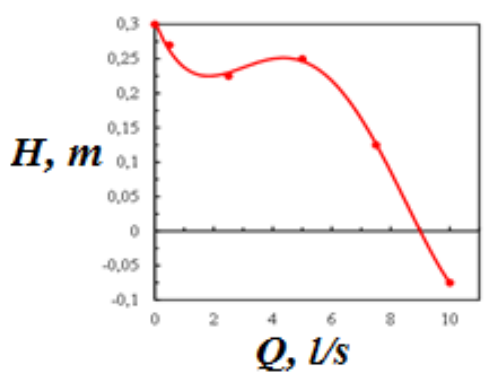

Fig. 12. Design head characteristic calculated in pump operation.

An analysis of the results gives reason to believe that the energy characteristics of microhydroturbines are reliable. With its further creation, taking into account operational requirements, indicators will be achieved no worse than with the original impeller.

\section{Improving the efficiency of microhydroturbine in the main mode of operation}

The increase in the efficiency of the hydraulic part of the combined energy complex was carried out using a new trend of nature imitation technologies which popular in the scientific world [7]. At the same time, special attention was paid to biological species whose habitat has similar characteristics with the area of operation of hydraulic machines. It was found that 
Humpback whales (figure 13) use the structural features of their pectoral fins, which have morphological outgrowths of a row arrangement at the leading edge.

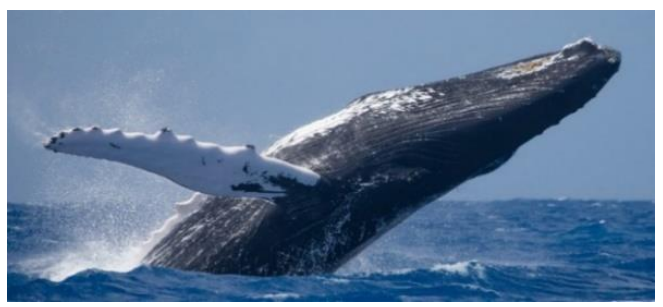

Fig. 13. Humpback whale fin structure photograph.

World researchers have suggested that these growths can contribute to a change in the flow hydrodynamics around the fin to increase its maneuvering efficiency. So, at the Brno University of Technology, computational studies were carried out [8] to establish the influence of the shape and size of these growths on the nature of the flow around the body (figure 14). It was found that the location, size and number of growths affect the flow conditions of the working bodies of microhydroturbines associated with the improvement of the flow hydrodynamic characteristics in the flow part.

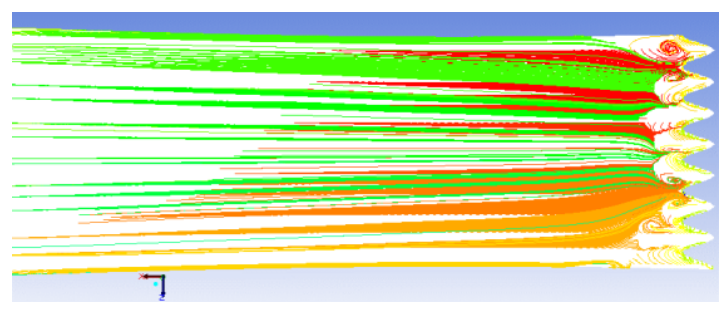

Fig. 14. Streamlines obtained by CFD modeling of surface flow processes similar to the structure of a humpback whale fin.

In order to experimentally test this approach, computational and experimental studies were carried out to transfer the new positive hydrodynamic properties of the "whale fin effect" to the working bodies of small and micro axial-type hydraulic turbines built-in the siphon penstock.

For these purposes, based on the geometry of the impeller, designed using classical approaches, an impeller was created having the original geometry of the input edge of the blades, made similar to the structure of the fin of a humpback whale (figure 15).

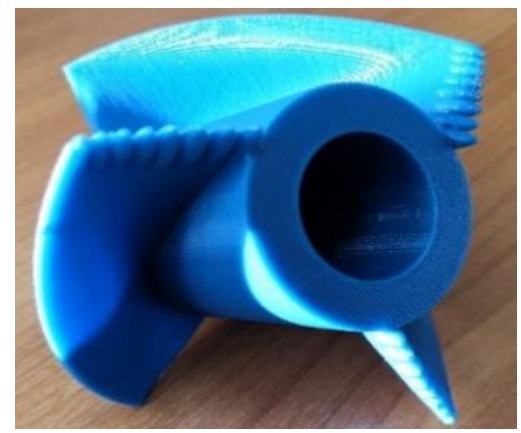

Fig. 15. Impeller with vane system which is improved using environmentally friendly technologies. 
Table 2 presents the comparative main parameters of the microhydroturbine obtained by the results of CFD modeling of work in the application package "FlowVision":

Table 2. Comparative energy characteristics of microhydroturbine.

\begin{tabular}{|c|c|}
\hline Impeller & Torque $\boldsymbol{M}_{\boldsymbol{t}} \mathbf{( N \cdot m )}$ \\
\hline Original $(z=3)$ & 0.152 \\
\hline Improved $(z=3)$ & 0.207 \\
\hline
\end{tabular}

In order to identify the correspondence of the impeller to the typical type of pressure characteristic, similar design studies were conducted in the pump mode, as before. Comparative results are presented in Figure 16.

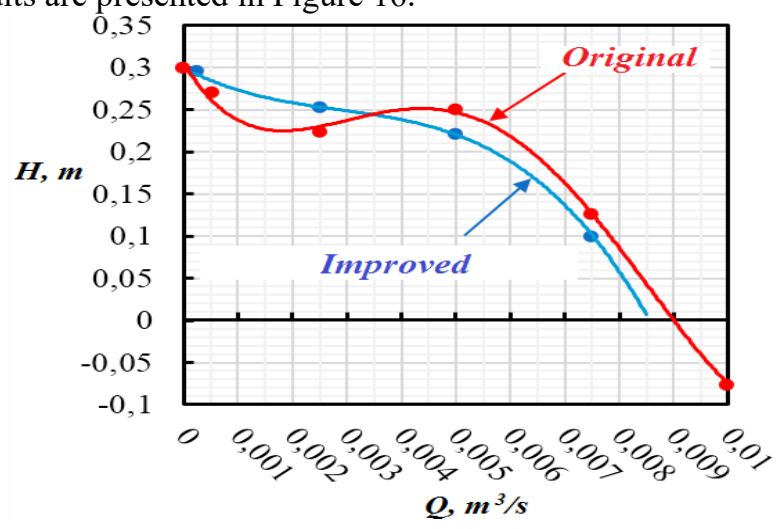

Fig. 16. Comparative calculated head characteristics in the pump mode.

The resulting pressure characteristic of the advanced impeller demonstrates close convergence in the medium and high feeds. The altered appearance of the curves in the lowfeed region shows some effect of growths on the input edge of the blades, but allows us to confirm a sufficient degree of reliability of the results.

The experimental approbation of approaches to improving the flow part was carried out using an MPEI experimental stand for studying the energy characteristics of microhydroturbines build-in siphon penstock. The hydraulic scheme of it is shown in figure 17.

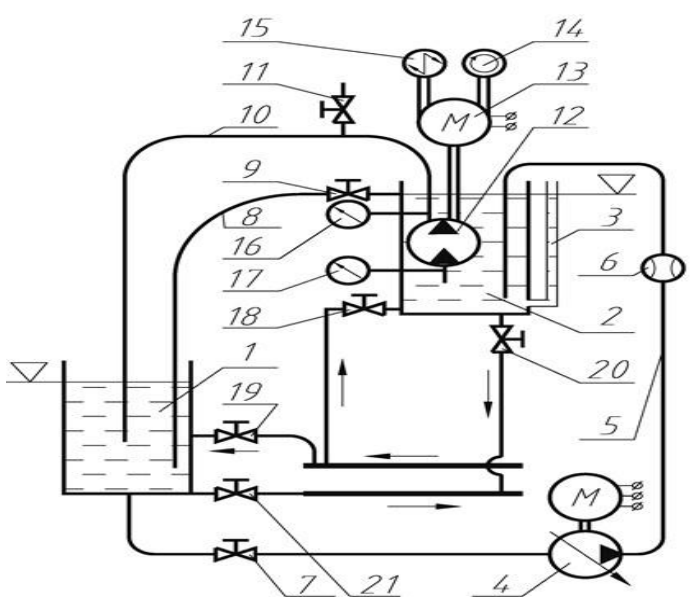

Fig. 17. Scheme of MPEI experimental stand for studying the energy characteristics of microhydroturbines: 1 - downstream reservoir; 2 - upstream reservoir; 3 - piezometer; 4 - pump unit; 5 - bypass pipeline; 6 - pump unit supply flow meter; 7 - hydraulic shutter; 8 - overflow discharge 
pipe; 9 - shutter for regulating the level of the upstream reservoir watermark, 10 - siphon penstock; 11 - breakdown of the vacuum valve; 12 - hydraulic microhydroturbine; 13 - eversible electric machine, 14 - shaft speed sensor; 15 - strain gauge for measuring torque on the shaft; 16,17 - manovacuometers of differential pressure on the impeller of a hydraulic micro turbine; 18,19 - pressure valves for filling the stand with liquid; 20,21 - valves for removing liquid from the stand.

To increase the reliability of the results of the study, 3 series of repeated experiments were carried out with each impeller of a microhydroturbine under the same conditions. For the characteristics of each impeller, a pair was found demonstrating the best repeatability of data based on a confidence level of $95 \%$. As a result of processing, the final energy characteristics of the microturbine in the form of a dependence of power on the rotational speed $N=f(n)$ are presented in figure 18 for original and improved impellers.

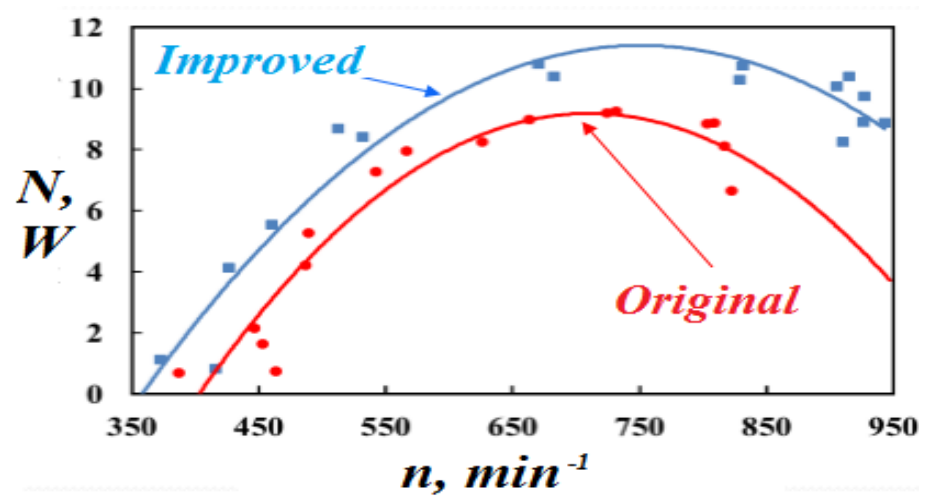

Fig. 18. Comparative characteristic $N=f(n)$ of a microhydroturbine with original and improved impellers.

Using this principle when creating a blade system of a microhydroturbine provides a more stable continuous flow around the blades and promotes the formation of stable vortices, changing the nature of the flow around the working side of the blades. This leads to a decrease in the risk of flow breaks and the formation of a flow structure which leads to a qualitatively lower hydraulic losses during flow. This is due to the increase in the generated power of a microhydroturbine with an improved impeller of $\sim 20 \%$.

\section{Conclusions}

The constructive scheme of the combined energy complex based on low-head (up to $2 \mathrm{~m}$ ) micro HPP is proposed, which is able to efficiently provide an autonomous consumer with both thermal and electric energy.

The method has been developed for a preliminary assessment of the energy complex hydraulic part efficiency taking into account losses in the penstock which allows predicting the energy characteristics of the complex at an early design stage.

Calculation and numerical and experimental studies of the model and maquette of the hydraulic unit were carried out to obtain its energy characteristics and verify their reliability.

The operability of the proposed combined energy complex hydraulic part scheme is proved.

The energy efficiency of the "whale fin effect" application for axial-type turbine blade systems has been confirmed. 
This work was financially supported by the Russian Federation Ministry of Science and Higher Education (unique project identifier is RFMEFI58618X0060) and by the Czech Republic Ministry of Education, Youth and Sports (unique project identifier is LTARF18).

\section{References}

1. A. V. Volkov, Ryzhenkov A. V., Parygin A. G., Naumov A. V., Druzhinin A. A., Vikhlyantsev A A, Šoukal J, Sedlář M, Komárek M, Pochylý F, Rudolf P and Fialová S., Matters Concerned with Development of Autonomous Cogeneration Energy Complexes on the Basis of Microhydropower Plants Thermal Engineering 65 799-805, 2018

2. A. A. Druzhinin, On the design of a pontoon low-head micro HPP Youth Scientific and Technical Bulletin 9 p 14, 2015

3. B. P. Ho-Yan, Design of a Low Head Pico Hydro Turbine for Rural Electrifi-cation in Cameroon MSc Thesis University of Guelph, Ontario, Canada, 2012

4. A. A. Lomakin, Centrifugal and axial pumps (Moscow: Engineering), 364 (1966)

5. V. V. Barlit, Hydraulic turbines (Kiev: Higher School), 360 (1977)

6. M. Varchola, Bielik T and Hlbočan P, Methodology of 3D hydraulic design of a impeller of axial turbo machine Engineering Mechanics, 20 (2), pp 107-118, 2013

7. A. V. Volkov, Ryzhenkov A v, Parygin A G, Naumov A v, Druzhinin A A, Vikhylantsev A A and Dasaev M R 2018 To the question about the prospects to the use of trigeneration energy sources based on hydropower Journal of Applied Biotechnology \& Bioengineering 5

8. Marcela Fojtíková, Design of high-specific speed hydraulic turbine with contoured shape of the runner blade MSc Thesis Brno University of Technology, Brno, 2013 